\title{
CORRESPONDENCE
}

\section{SIDE-EFFECTS OF TOPICAL THERAPY WITH OPTRANE}

\author{
To the Editorial Committee of the British Journal of Ophthalmology
}

SIRS,-Within recent years there has been a little renewed interest in the treatment of seborrhoeic blepharo-conjunctivitis other than by modifications of the time-honoured methods, e.g. selenium sulphide (Quintieri, 1955; Selfa, 1958), and more recently Octrane (Penotrane) (Jackson, 1965).

We had Octrane on trial during the period August, 1965, to February 1966, when thirteen patients who were thought to be suitable for this treatment were examined. The results were by no means dramatic, and as success in treating this condition can be obtained by simple mechanical cleansing alone, it may be necessary to assess therapy on side-effects and on the lack of good response (Wong, Fasanella, Haley, Marshall, and Krehl, 1956).

Of our thirteen patients, five suffered from irritation and all from allergy. We feel that this incidence of side-effects is too high, even though none of these was serious. All patients had the treatment for only a short time.

December 16, 1966.

Yours faithfully,

BRISTOL EYE HOSPITAL,

V. J. Marmion and M. Silva.

LOWER MAUDLIN STREeT,

BRISTOL, 1.

\section{REFERENCES}

JACKSON, B. (1965). Brit. J. Ophthal., 49, 307.

QUINTIERI, C. (1955). Boll. Oculist., 34, 687.

Selfa, E. (1958). Rev. esp. Oto-neuro-oftal., $17,501$.

Wong, A. S., Fasanella, R. M., Haley, L. D., Marshall, C. L., and Krehl, W. A. (1956). Arch. Ophthal. (Chicago), 55, 246.

\section{BOOK REVIEWS}

System of Ophthalmology. Edited by S. Duke-Elder. Vol. IX. Diseases of the Uveal Tract. By S. Duke-Elder and E. S. Perkins. 1966. Pp. 978, 815 figs, bibl. Kimpton, London.

This volume, forming one part of the fifteen-volume "System of Ophthalmology", deals with the diseases of the uveal tract. Inevitably certain pathological conditions lie on the fringes of the subject. The authors state that it is their intention to deal with all diseases which occur primarily in the uveal tract. Difficulty arises in connexion with diseases of the retina. Those which are primarily uveal though the symptoms are due to retinal lesions are discussed in this volume, and certain infections such as Toxoplasma gondii and Toxocara canis which usually commence in the retina and which cause many uveal symptoms and signs have been included among uveal inflammations. General infections of the eyeball such as panophthalmitis and endophthalmitis are also included. It is interesting to find that the epithelial tumours of the uveal tract are classified as benign and malign. The latter term has a clear meaning but it is not usually used in pathological descriptions.

The general arrangement of the book is, of course, beyond criticism, and lists of references on all subjects are very complete. The illustrations are excellent (though plate XI in the review copy has been inserted upside-down) and the references from the text are clear and concise. 